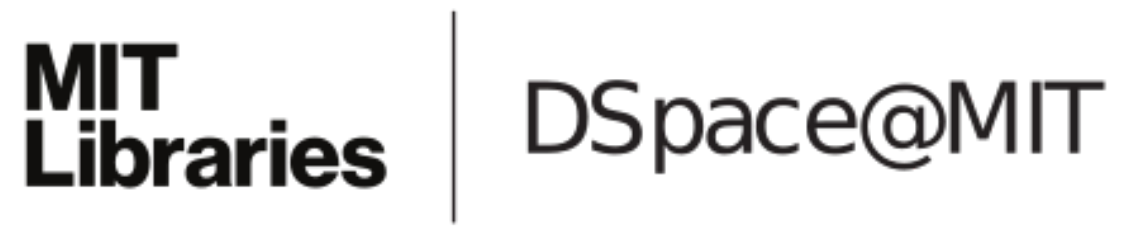

\author{
MIT Open Access Articles
}

Spatiotemporal Dynamics in Public Transport Personal Security

Perceptions: Digital Evidence from Mexico City's Periphery

The MIT Faculty has made this article openly available. Please share how this access benefits you. Your story matters.

Citation: "Spatiotemporal Dynamics in Public Transport Personal Security Perceptions." ICT for Transport, Edward Elgar Publishing, 2015, pp. 115-39.

As Published: http://dx.doi.org/10.4337/9781783471294.00014

Publisher: Edward Elgar Publishing

Persistent URL: http://hdl.handle.net/1721.1/112296

Version: Author's final manuscript: final author's manuscript post peer review, without publisher's formatting or copy editing

Terms of use: Creative Commons Attribution-Noncommercial-Share Alike 
Author's final version of Chapter 5 in:

ICT for Transport: Opportunities and Threats (P. Rietveld, M. Givoni, N. Thomopoulos, Eds) Edward Elgar (2015), pp. 115-139. DOI: 10.4337/9781783471294.00014

\title{
5. Spatiotemporal dynamics in public transport personal security perceptions: digital evidence from Mexico City's periphery
}

\author{
P. Christopher Zegras, Kuan Butts, Arturo Cadena and Daniel Palencia
}

\section{$1 \quad$ INTRODUCTION}

The potential for information and communication technologies (ICTs) to revolutionise transportation is of long-standing interest. Just as the telegraph, trans-oceanic cable communications, the telephone, and the fax surely influenced travel behaviours and supply of transportation infrastructures and services, related developments, especially in computing, have changed the way we analyse and plan systems. The most recent wave of ICT-related technological advances - epitomised by high-powered sensing and realtime computing capabilities - promises a new era of seamless services, autonomous vehicles, and high resolution system micro-simulation, to name a few emerging opportunities.

In this chapter, we demonstrate the potential offered by one particular advanced ICT instrument, the smartphone, to improve our abilities to diagnose urban mobility problems. Our empirical setting is one of the world's great 'megacities', and our research topic is personal security, in particular users' perceived security reported on public transportation services. Our fundamental ICT-related aim is to test the value of the smartphone as a diagnostic tool to ultimately improve transport services, particularly in a megacity context. Our broader inquiry aims to under- stand what influences perceptions of personal security on public trans- port services in suburban Mexico City, with a specific focus on whether recently developed intermodal transfer stations and some of their related technological and design elements might play a role.

\section{Technological Background: Smartphone-Based Mobility Data Collection}

Because of their ubiquity, portability and sensing capabilities, today's mobile phones can be a great source of data about individuals' mobility demand. Mobile phones' general ubiquity has made records from telecom companies one form of large-scale, though low-dimensional (for example, low spatial resolution, no user information), data source. Gonzalez et al. (2008), for example, analysed thousands of mobile phone user records and observed highly regular daily travel patterns, as revealed by the cellphone tower locations of the phone's calling or texting activities. Today's so-called 'smartphones' - with advanced computing, networking (that is real-time data communications), and sensing (for example, GPS, accelerometers) capabilities and the ability to run programs (that is 'apps') and browse the web offer a high-resolution means for purposeful, 'bottom up' data collection. Cottrill et al. (2013), for example, aim to replace traditional travel survey methods with a specialised app to non-intrusively (that is requiring minimal user interaction) collect location traces (using GPS, Wi-Fi, and cell tower locations) and accelerometer data; combined with a back-end, server-based intelligence the goal is to detect travel modes, stops, trip origins and destinations, and purposes. Jariyasunant et al. (2014) take a similar technological approach to Cottrill et al. (2013), but with the aim of providing feedback to the users (on, for example, their carbon footprint, calories burnt) to explore possible behavioural and attitudinal influences. 
With small screens allowing data entry, smartphones also hold promise for improving contextual richness and multi-dimensionality of field data collected for other types of mobility analyses, such as onboard surveys and traffic counts. In theory, heterogeneous, high-resolution field data can be rapidly collected, transmitted, fused and validated almost simultaneously. For example, passenger counts can be combined with on-board surveys, which can be precisely matched with time and place stamps and transmitted remotely to databases. In traditionally data-sparse settings, such as much of the global south, some of these capabilities have already been deployed to, for example, generate public service inventories in rural Nigeria (Berg et al., 2013). Special-purpose apps have also emerged to facilitate mapping public transportation services. TransitWand, for example, uses GPS signals to track a user's location and allows the user to collect stops, boarding/alighting times, and passenger counts. Users manually upload this information using Wi-Fi or cellphone networks; authorities in Mexico City recently used TransitWand to map semi-formal transit services in the city (Eros et al., 2014).

In January 2012, a research team at MIT in collaboration with a local organisation set out to test smartphone capabilities for understanding public transportation operations (mapping routes, speeds, stops) and con- ducting on-board surveys and passenger counts in Dhaka, Bangladesh. Subsequent improvements to the technologies and concentrated deployment of a volunteer team resulted in the development of the city's first widely available map of the city's semi-formal, privately operated public transport routes, released in paper and electronic form in May, 2013 (Zegras et al., 2015). We subsequently adapted the technology, described in more detail below, for testing in another of the world's megacities, Mexico City.

\section{RESEARCH CONTEXT AND QUESTIONS}

The Mexico City metropolitan area ${ }^{1}$ is one of the world's largest megacities, with some 20 million people spread across at least $4000 \mathrm{~km} 2$. The city's multimodal passenger transportation system includes one of the world's largest urban rail systems (Metro), an extensive, privately operated and loosely regulated system of minibuses (a range of vehicle types, generally referred to as colectivos), a five-line (as of 2014) bus rapid transit (BRT) system first introduced in 2005, and approximately 5.4 million private cars. As of the last household travel survey, in 2007, colectivos accounted for nearly 50 per cent of the city's motorised person trips (SETRAVI, 2010). Colectivos include combis, modified vans with inward-facing seating along the periphery of the internal cabin; and peseros (or minibuses), with larger capacity than the combis, and with front-facing seat rows.

Among the range of challenges facing the area's mobility system looms personal security concerns, or fear of crime. ${ }^{2}$ Research suggests that fear of crime on public transport arises from perceived vulnerabilities, a result of factors over which passengers have little control (Yavuz and Welch, 2010). These factors might include vehicle and station appearance, service reliability, presence of security technologies and police, personal charac- teristics (e.g., age, gender) and experiences, and trip characteristics (Yavuz and Welch, 2010). In the UK in the 1990s, authorities estimated that fear of crime suppressed 3 per cent to 10 per cent of public transport demand (Newton, 2004). Gender plays an important role, with women's personal security needs and concerns long recognised as being different from men's (Lynch and Atkins, 1988; Smith, 2008). Women, for example, may fear sexual harassment

\footnotetext{
${ }^{1}$ We use Mexico City to refer to the Metropolitan Area of Mexico City.

${ }^{2}$ We use the word 'security' to refer to crime and fear of crime, not traffic safety (although traffic safety problems can result from criminal activities).
} 
(for example, GDF, 2011; Hsu, 2011); men, on the other hand, may actually under-report their personal security concerns (for example, Sutton and Farrall, 2005) and may be more susceptible to police harassment/corruption. ${ }^{3}$ Newton (2004) suggests the need to develop techniques to better analyse the linear patterns of public trans- port crime (and, by extension, fear of it), including internal and external environments of the routes, corridors, stops and stations; similarly, Smith (2008) advocates the 'whole journey approach' to analyse the 'dynamic and complex environment' (p. 129) influencing fear of crime.

While not widely studied in the academic literature, Mexico City's transportation-related personal security concerns are evident. As Davis (2007) states, the city's 'citizens have become so fearful of crime that they are changing where and how they live, travel, and interact with their fellow citizens' (p. 67); reportedly 48 per cent of residents avoid public transport due to fear (Davis, 2007). Women are particularly at risk; women com- prised 95 per cent of the 850 victims of reported incidents on the Metro from 2008 to 2010 (GDF, 2011); the Metro has women-only cars and platform areas during rush hours and women-only buses were introduced in 2008 and by 2011 covered 50 bus routes carrying 25000 passengers on an average work day (GDF, 2011).

\section{CETRAMs: An Experimental Opportunity}

Approximately 40 per cent of the metropolitan area's population resides in the Federal District (Distrito Federal or DF), the nation's capital and the historic economic, cultural and financial hub of the region and the country. The remainder of Mexico City's residents sprawl across a landscape of some 40+ municipalities in the surrounding State of Mexico. Functionally, this jurisdictionality is important since buses and colectivos, which provide the major share of public transportation services outside the DF, cannot legally operate in the DF. Thus, bus and colectivo users traveling from the broader metropolitan area into the DF must transfer at the border, typically at intermodal transfer centres, known as CETRAMs (Centros de Transferencia Modal). ${ }^{4}$ As of mid-2013 (the time of the fieldwork presented below), 46 CETRAMs functioned in the DF, 39 of which interface with Metro and BRT stations. The DF's CETRAMs serve roughly five million passengers each day (approximately 40 per cent from outside the DF), making them the city's most-used public transport facilities (GDF, 2011).

Despite their intense utilisation, most CETRAMs remain little more than large parking lots. A recent report conducted for the DF (GDF, 2011), evaluating the design and implementation of public transport policy in the city, highlights a range of CETRAM problems including inadequate design and infrastructures, lack of maintenance, high levels of congestion, poor administration, disorganised informal commerce, and poor levels of public security, especially for women. The DF government strategy to improve CETRAM conditions and functioning includes public-private partnerships (PPPs) to transform CETRAMs into urban spaces that not only improve the passenger transfer experience, but offer a range of formal commerce and services, provide employment opportunities, improve the urban surroundings, and increase security (GDF, 2011).

\footnotetext{
${ }^{3}$ We could find no academic literature supporting this concern in Mexico City; however, our field work produced anecdotal evidence that men on colectivos were more likely to be subject to police 'shakedowns' (vehicles being stopped and men being pulled off by police and forced to pay 'fines').

${ }^{4}$ Note that not all CETRAMs are on the periphery; many function at intermediate Metro stations. In addition, not all CETRAMs are technically inter-modal, as some just provide transfers between different services of the same mode.
} 
We examine two pioneering CETRAMs, developed by private investors under 30-year PPP concessions: El Rosario, inaugurated in May 2013; and Mexipuerto (also known as Ciudad Azteca), inaugurated in November 2009. The same developer developed and operates, under separate concessions, both CETRAMs, with most income coming from rents from the various real estate activities, which include movie theatres, retail, and social services, including a medical clinic in the Mexipuerto case. Security measures employed include closed circuit television and private security personnel. Both provide intermodal links with Metro lines; Mexipuerto also integrates with a BRT terminal station.

Located on the northwest (El Rosario) and northeast (Mexipuerto) boundaries of the DF, the CETRAMs are situated in different jurisdic- tions: El Rosario in the DF delegación ${ }^{5}$ of Azcapotzalco, and Mexipuerto in the State of Mexico muncipio of Ecatepec (Figure 5.1). This implies different public security authorities and different regulatory authorities and operating procedures within the CETRAMs. At El Rosario, for example, the DF manages vehicle activity within the terminal, whereas at Mexipuerto the concessionaire manages the intermodal services, for a fee to the vehicle operators (taxes, buses, colectivos) collected through a radio-frequency identification (RFID) based toll system.

The areas that the two CETRAMs serve are somewhat different, socio- economically and demographically (Table 5.1). ${ }^{6}$ Located in Ecatepec, one of the oldest and largest suburban municipios of Mexico City, Mexipuerto serves a much larger population, although with lower density than El Rosario, with a higher share of children and lower share of older adults. The Mexipuerto service area has lower unemployment, but also lower household motorisation rates. In the immediate station area vicinities, El Rosario has become more service-oriented in the past decade, with a newly completed multi-storey mall directly adjacent and two large housing complexes, two technical high schools and a university campus nearby. Adjacent to Mexipuerto is 'Multiplaza Aragon', one of Mexico City's largest shopping centres, first opened in 1971, and anchor to Ecatepec's main commercial corridor.

The two CETRAMs have comparable amounts of space - approximately $70000 \mathrm{~m} 2$ each of real estate. Architecturally, some differences arise. El Rosario is more akin to a 'fortress in the air', with limited, gated entrances to the central structure, leading consumers to the second floor commercial areas and primarily accessible only by off-boarding bus commuters or Metro riders. Street access is limited via two back stairwells controlled by armed guards. Mexipuerto presents a more open façade to the immediate surroundings. As mentioned previously, the vehicle management schemes in the two CETRAMs also differ. El Rosario functions traditionally, with few improvements over the pre-concession site; the DF is responsible for management, from an on-site office and via random vehicle verification. In contrast, at Mexipuerto all vehicles entering the facility must carry an RFID chip, which the concessionaire uses to charge the transit operators for use of the facility as well as to organise vehicles within the facility (at passenger loading bays and so on) - a form of on-site intelligent transpor- tation service (ITS). Both stations service roughly 10000 vehicles per day, with El Rosario handling over 180000 passengers per day and Mexipuerto handling about 110000 passengers per day.

\footnotetext{
${ }^{5}$ Delegaciones are sub-districts in the DF.

${ }^{6}$ Information on the approximate CETRAM service areas was gathered by taking the point location of the on-board surveys conducted and linking that point to the census tract it contained.
} 


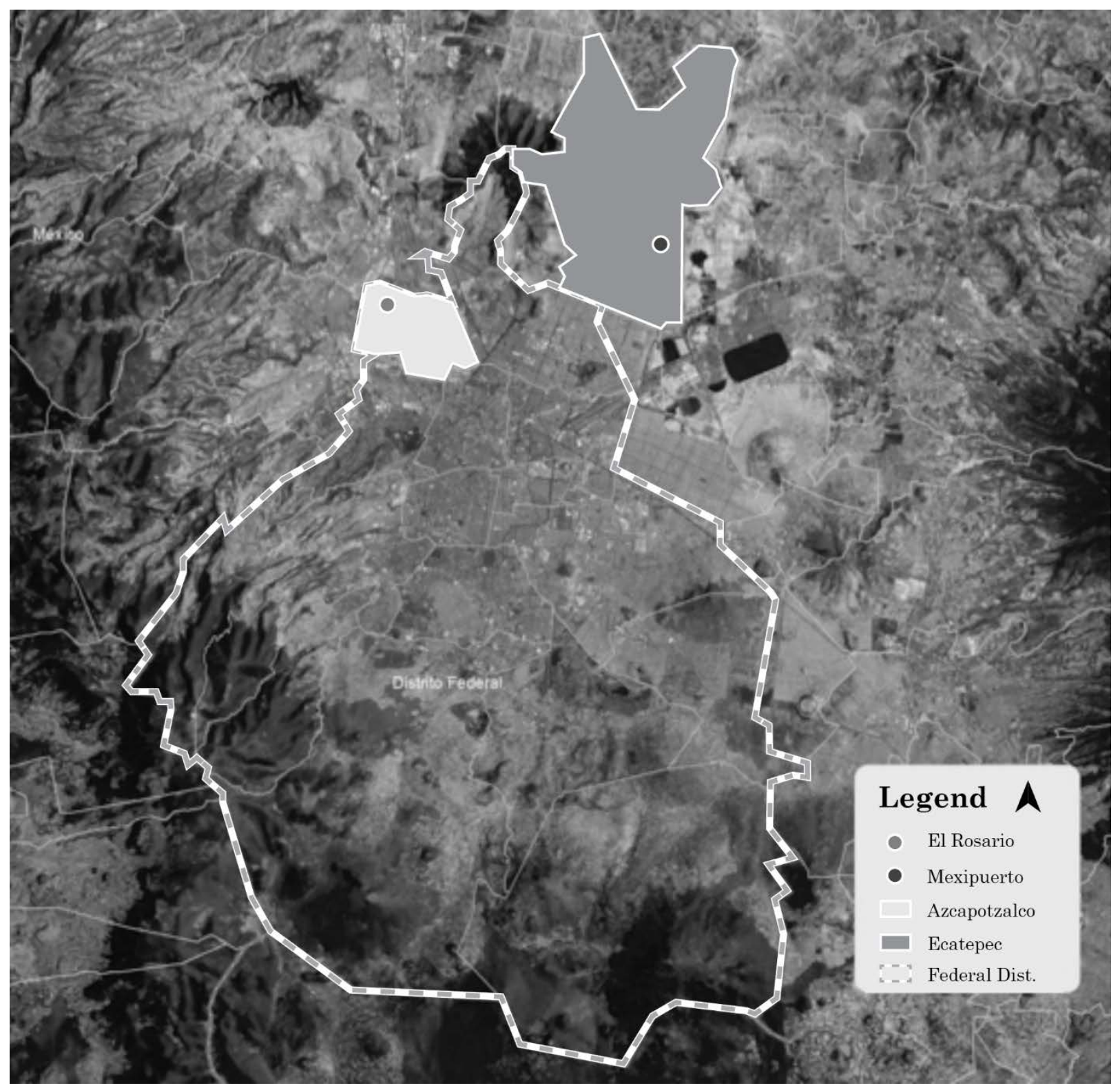

Figure 5.1: The locations of the two CETRAMs in the metropolitan area. 


\begin{tabular}{|l|r|r|}
\hline Variable & El Rosario & \multicolumn{1}{|c|}{ Mexipuerto } \\
\hline Population & 211,430 & 418,178 \\
\hline Population density (persons/hectare) & 160.6 & 116.5 \\
\hline Share female & $52.4 \%$ & $51.6 \%$ \\
\hline Population 0-14 years old & $18.7 \%$ & $27.3 \%$ \\
\hline Population 15-64 years old & $67.4 \%$ & $67.0 \%$ \\
\hline Population 65+ years old & $9.2 \%$ & $4.8 \%$ \\
\hline Economically active population & $43.7 \%$ & $42.4 \%$ \\
\hline Unemployment rate & $6.1 \%$ & $4.9 \%$ \\
\hline Occupants/house & 3.6 & 3.7 \\
\hline Vacant housing & $14.3 \%$ & $26.0 \%$ \\
\hline Share households with motor vehicle & $54.1 \%$ & $36.5 \%$ \\
\hline $\begin{array}{l}\text { Percentage of population with at least 1 year of } \\
\text { university education }\end{array}$ & $25.0 \%$ & $29.8 \%$ \\
\hline
\end{tabular}

Table 5.1: Socioeconomics and demographics along routes CETRAMs. Sources: INEGI, 2010, 2000.

\section{Research Questions}

In light of Mexico City's goals of enhancing CETRAMs to improve public transport system services, the surrounding environment, the user experience and public security, we aim to examine these new, enhanced CETRAMs with a particular focus on personal security. We attempt to measure individuals' perceived security as self-reported in a survey, aiming to represent fear of physical violence, crime or other social intimi- dation (Davis, 2013). In the Mexico City context, the CETRAMs offer a relevant lens on the security question, representing the private sector use of real estate, security forces and technological surveillance, which have been increasingly deployed towards security enhancements in the city (for example, Davis, 2007; 2013). In particular, we aim to answer the following questions:

- Are the new CETRAMs increasing the sense of security among public transport users? If so, does this effect endure over dis- tance from the CETRAM and/or vary by CETRAM management approach?

- Do perceptions of personal security on public transport vary accord- ing to the surrounding environment of the routes?

- What relationships exist between individual characteristics (for example, age, education), security concerns and awareness, and how do trip characteristics relate to perceived personal security?

- Do ICT technologies related to CETRAM management have a role in personal security perception among public transport users?

- Finally, do factors associated with security perceptions vary by gender?

We attempt to answer these and other questions through deployment of a smartphone-based field data collection tool in an attempt to answer the meta-question: can new ICT technologies improve urban mobility diagnostics? 
To answer the research questions, we adapted our smartphone-based app originally used for mapping Dhaka's public transportation (Zegras et al., 2015). The Android app was designed in MIT App Inventor, a free, web-based service intended to make app programming easy. ${ }^{7}$ Key enhancements to the Dhaka app included making the survey component within the smartphone app more stable (less prone to crashes), which is key to consistent surveying and matching surveys to geospatial and temporal information. Our app, dubbed 'Flocktracker', used App Inventor's built-in GPS call function, which attempts to geolocate the phone's position every 30 seconds. This locational functionality was not perfect, as 30 -second marks were sometimes missed, either because the process timed out, was interrupted by subsequent commands, ${ }^{8}$ and/or did not find a GPS signal. These problems hampered location accuracy during the course of the surveys. The relatively high GPS sampling frequency (30 seconds) meant that battery power with the app running non-stop sufficed for 5 to 6 hours of operation, enough to last the surveying shifts, but also a constraint.

Within the app, we designed a 12-question survey to collect interviewees' opinions regarding security (including perceptions of security at the point of the interview, importance of security in travel mode choice, perspective regarding relative security of different travel modes), technological awareness and perceptions (that is, knowledge of RFID-equipped colectivos and opinions regarding impacts on one's security), other relevant individual characteristics (age, gender), and trip characteristics (purpose, origindestination, number of companions). The questionnaire was designed to be implemented on-vehicle along colectivo routes. Thus, speed and ease of implementation was a key specification. The app also allowed the surveyor to count the number of on-board passengers, by gender, and enabled automatic collection of location and temporal data (Figure 5.2). These data were uploaded every 30 seconds to an on-line database (as a Google Fusion table), for storage security and robustness. Not only were we able to directly associate survey and count data with spatiotemporal data, but the approach also enabled an almost real-time monitoring of the surveyors' locations (through a web-based interface, Figure 5.3), which, among other benefits, allowed surveyors' progress to be monitored and guided.

\section{Sampling Design and Implementation}

The surveys were conducted by approximately 30 university student volunteers from MIT and the National Autonomous University of Mexico (UNAM). For each of the two CETRAMs, we selected two colectivo routes, one which utilised the CETRAM and a second which closely follows the latter's route, but without entering the CETRAM. This design was intended to test the CETRAM versus no-CETRAM effect and possible differences in effects between the two CETRAMs, while roughly controlling for neighbourhood-level characteristics. At El Rosario, the route was roughly 14 kilometres, while at Mexipuerto the route was roughly 16 kilometres. In the Mexipuerto case, the same company operates nearly identical routes that service the sprawling suburban neigh- bourhood north of the CETRAM. Some of the vehicles enter the station while others simply pick up users along the side of the broad thoroughfare adjacent to the station. Thus, the routes are essentially the same along the primary

\footnotetext{
${ }^{7}$ We used App Inventor 1, the version available as of May 2013. See: appinventor.mit.edu.

${ }^{8} \mathrm{~A}$ limitation in our use of App Inventor was that only one call function could be called at a time - for one action to occur, all others had to be stopped.
} 
portion of the route, and all tend to meander according to demand, time of day, and reports from other operators. Figure 5.4 depicts the routes examined for both CETRAMs.
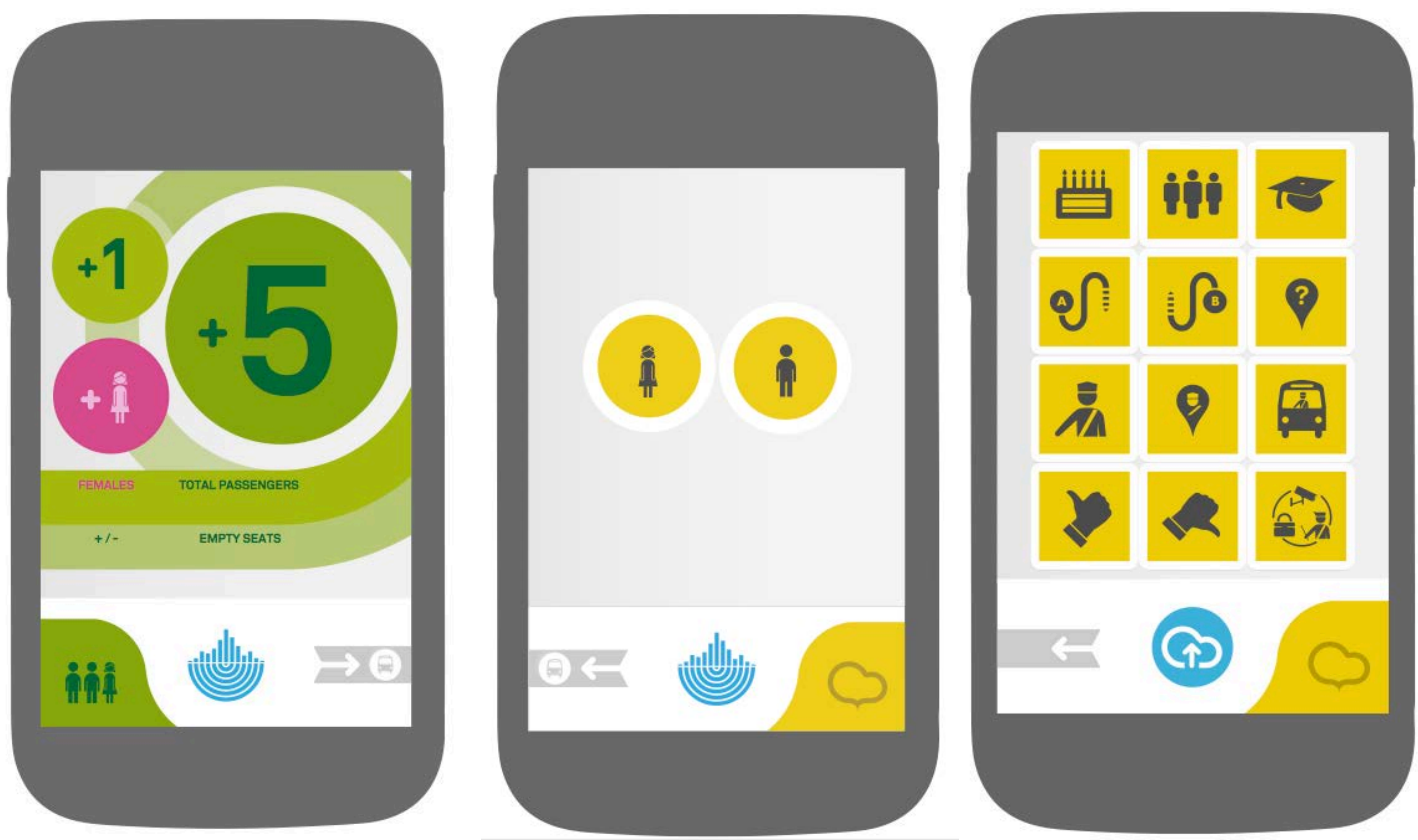

Figure 5.2: Images of the app interfaces for (from left) passenger counting, noting gender (survey initiation), and entering individual survey questions.

Bus Number: Show All Show: Last Known date :

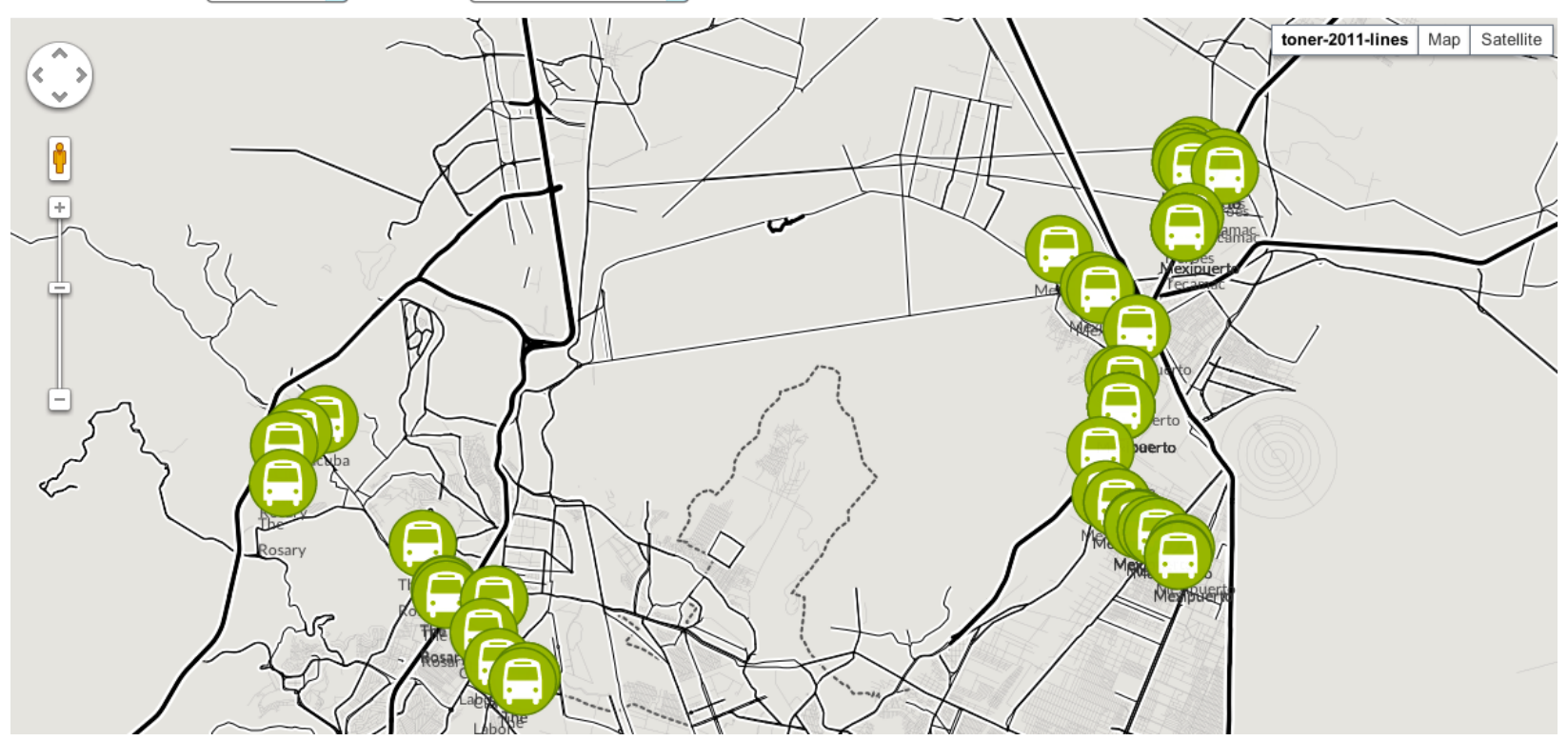

Figure 5.3: Screen capture of web-based monitoring system to locate surveyor locations while in the field.

The volunteers conducted the surveys in groups of two (for personal security reasons), during one of two shifts during the day: an off-peak period from 12:00 pm to $3 \mathrm{pm}$ and an evening peak period from 
4:00 pm to 7:00 pm. The shifts were intended to keep volunteers from riding at night, especially once it was dark. Surveying occurred over a one-week period in mid-July, 2013. Volunteers wore uniformed shirts for identification pur-poses and were instructed to attempt to interview everybody on-board the vehicle. The survey required between one and three minutes to implement per observation.

\section{Data Collection Results}

The survey effort resulted in roughly 650 volunteer hours, an average of 90 hours of surveying per day, producing 10977 cleaned data points along the four routes, with 1528 interviews performed in total. Of these interviews, 1018 were performed on-board colectivos, the observations of interest in our analysis. The spatial and temporal data revealed little vari- ation in travel speeds, with the average typically above $20 \mathrm{~km}$ per hour. Additional data collected to complement the app-based survey and vehicle condition data were observation-based, urban typology characterisation of the route surroundings. Admittedly crude, eight characterisations were operationalised, representing roadway and physical form (street types, pedestrian-orientation).

The Appendix presents the variables used in our analysis and their descriptive statistics. Given the importance of gender in public transportation security, we present the statistics separately for females and males. The data reveal the majority of observed trips were by combi, split roughly equally among the two CETRAM areas. Between one-fifth and one- quarter of the trips were on vehicles that passed through CETRAMs. The majority of the individuals were between 25 and 64 years old, with only slight variation by gender, and the majority were traveling alone, although a larger share of men than women were unaccompanied. Female travellers were more likely to be on shopping trips and men on work trips.

Expectedly, women had lower reported levels of security on their travel mode, in general, but only modestly lower levels of reported security at the point of the interview. All respondents overwhelmingly rated security as important in mode choice, again with slightly more women placing high importance on this attribute; both men and women ranked peseros as the least safe public transport mode and the Metro as the safest. Nearly two- thirds of all respondents were unfamiliar with the RFID tag system on colectivos; among those who knew about it, most were neutral regarding its impacts on security. More than half of respondents in the Mexipuerto service area were familiar with the RFID-equipped vehicles (56 per cent of females and 60 per cent of males). Oddly, fewer colectivo riders on RFID vehicles (that is, using the Mexipuerto CETRAM) knew about the RFID than those on non-RFID vehicles. 

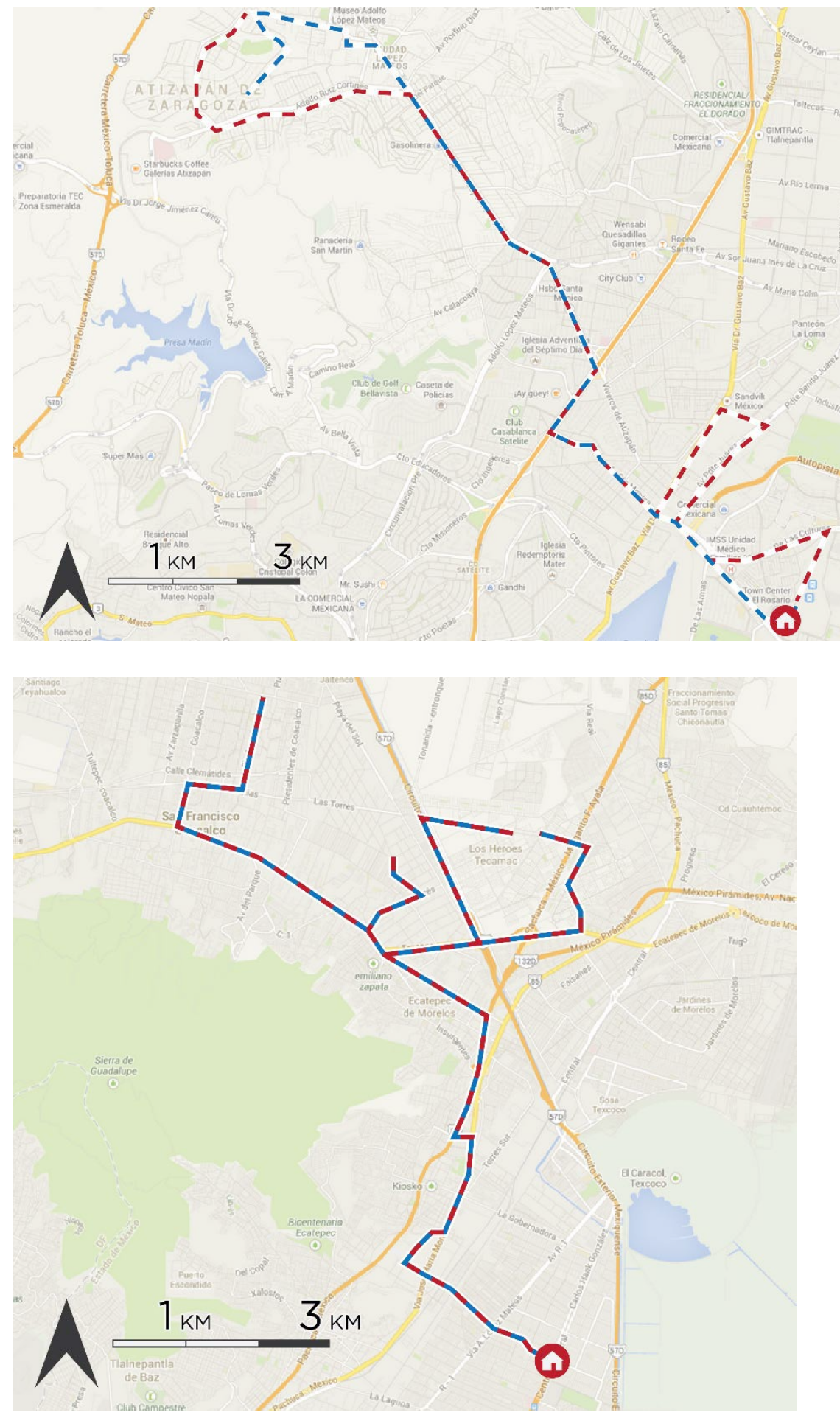

Figure 5.4: Map of surveyed colectivo routes emanating from El Rosario (top) and Mexipuerto (bottom). Notes: In the El Rosario map, dashed portions indicate divergent paths for route operations inside and outside of the CETRAM. The solid portion represents that common to both routes. In the Mexipuerto map, the various pathways represent route deviations. 
We now attempt to discern the contributing factors to on-board public security perceptions among the colectivo passengers in the two study areas, examining the role of CETRAM-based routes, individual characteristics, and trip-based characteristics. As our outcome, respondents' ranking of their public security level, is ordered, we specify and estimate an ordered probit model, clustering the standard errors to account for riders in the same vehicle. Table 5.2 presents the results of the best model.

\begin{tabular}{|c|c|c|c|c|c|}
\hline Variable & Description & Beta & S.E. & Z-Score & p-value \\
\hline \multicolumn{6}{|c|}{ Survey Location: CETRAM } \\
\hline Mexipuerto & Mexipuerto Study Area & -0.58 & 0.12 & -5.00 & 0.00 \\
\hline \multicolumn{6}{|c|}{ Survey Location: Urban Typological Context } \\
\hline CETRAM & CETRAM proximity & 0.67 & 0.14 & 4.86 & 0.00 \\
\hline Ped_Ave & Pedestrian-Friendly Ave. & 1.12 & 0.49 & 2.27 & 0.02 \\
\hline F_Ped_Ave & Female on Pedestrian-Friendly Ave. & -1.03 & 0.59 & -1.75 & 0.08 \\
\hline Ped_Street & Pedestrian Street & 0.37 & 0.14 & 2.64 & 0.01 \\
\hline Res_Streets & Residential Street & 0.36 & 0.10 & 3.45 & 0.00 \\
\hline Suburb_Comm & Suburban Commercial & 0.89 & 0.17 & 5.31 & 0.00 \\
\hline Industry & Industrial Zone & 0.35 & 0.21 & 1.67 & 0.09 \\
\hline Express & Expressway & 0.36 & 0.11 & 3.34 & 0.00 \\
\hline \multicolumn{6}{|c|}{ Auto-oriented Ave, Ped-oriented Secondary - Reference } \\
\hline \multicolumn{6}{|l|}{ Trip Characteristics } \\
\hline F_companions5 & Female with $5+$ Companions & -0.56 & 0.26 & -2.16 & 0.03 \\
\hline Combi & Trip on Combi (van) & 0.48 & 0.11 & 4.25 & 0.00 \\
\hline F_School & Female School Trip & 0.57 & 0.15 & 3.69 & 0.00 \\
\hline \multicolumn{6}{|c|}{ Trip-Maker Characteristics } \\
\hline Female & Female & -1.11 & 0.22 & -5.02 & 0.00 \\
\hline age_0_17 & Age $0-17$ years old & 0.22 & 0.12 & 1.80 & 0.07 \\
\hline Ed_PostGrad & Post Graduate Education & -0.34 & 0.20 & -1.71 & 0.09 \\
\hline RFID_4 & $\begin{array}{r}\text { RFID has positive Security Impact (4 of } \\
5 \text { ) }\end{array}$ & 0.60 & 0.17 & 3.43 & 0.00 \\
\hline RFID_No & Unaware of RFID devices & 0.30 & 0.14 & 2.14 & 0.03 \\
\hline F_RFID_5 & $\begin{array}{r}\text { For Female RFI has positive security } \\
\text { impact ( } 5 \text { of } 5 \text { ) }\end{array}$ & 0.87 & 0.21 & 4.06 & 0.00 \\
\hline F_RFID_No & For Female, Unaware of RFID & 0.40 & 0.17 & 2.41 & 0.02 \\
\hline Impt_Security_4 & $\begin{array}{r}\text { Importance of security in mode } \\
\text { choice (4 of 5) }\end{array}$ & 0.97 & 0.17 & 5.53 & 0.00 \\
\hline Impt_Security_5 & $\begin{array}{r}\text { Importance of security in mode } \\
\text { choice (5 of } 5 \text { ) }\end{array}$ & 0.42 & 0.18 & 2.37 & 0.02 \\
\hline F_Impt_Security_5 & $\begin{array}{r}\text { For Female, Importance of security in } \\
\text { mode choice ( } 5 \text { of } 5)\end{array}$ & 0.66 & 0.20 & 3.35 & 0.00 \\
\hline
\end{tabular}

$\mathrm{N}=1018 ;$ pseudo- $\mathrm{R}^{2}=0.08 ;$ log pseudolikelihood $=-1531.87$

Table 5.2: Ordered probit model of colectivo riders' security perceptions. 


\section{CETRAM- and Urban Context-related Relationships}

The results suggest that, consistent perhaps with the overall lower income of the service area, users of the Mexipuerto service area consider it less secure than do users of the El Rosario service area, irrespective of gender. The urban typology relationships are evaluated relative to auto-oriented avenues, and pedestrian-oriented secondary streets. Relative to those, the redeveloped CETRAMs' surroundings have a positive relationship with colectivo users' security perceptions, as do all of the other urban typological contexts. The exception to this is pedestrian avenues for women, which essentially is no different from the reference. We cannot come to any real conclusions from these results except to say that context does apparently matter with respect to public transport users' security perceptions - an area worth additional study.

\section{Trip- and Individual-Related Characteristics}

For female passengers, traveling with five or more companions is associated with feeling less secure $(p=$ 0.03). At least two explanations may exist for this result: females inclined towards feeling less secure may travel in larger groups; alternatively, females feeling less secure may, in fact, misrepresent their number of traveling companions as a safety precaution. Relative to work, shopping, recreational or other trips, being a female on a school trip is associated with a higher sense of security; no trip-related effects are detected specifically for men. Riding on combis is associated with reporting higher levels of security relative to riding on larger peseros. Conversations with some individuals riding the combis suggested that the awkward nature of entering the vehicle (sliding door had to be opened from the inside) versus the ease of access of a pesero and the lower capacity and relative crowding of the smaller vehicles made them harder to board and alight from and more 'intimate' for those on-board. These factors might combine to make it harder for assaults to take place on combis, explaining the higher perceived levels of security. Security perceptions do not vary by peak/off-peak periods.

Controlling for other individual characteristics, being a woman is associated with reporting lower personal security levels. Only the youngest age group had a statistically significant relationship $(p=0.07)$ with perceived security; this positive relationship might reflect an 'invincibility of youth' belief. For both males and females, education levels had the same effect: having a post-graduate education (albeit representing a small share of individuals in the sample) is associated with lower security perceptions $(p=$ 0.09). Those who ranked security as highly important (4 or 5 ) in the mode choice decisions actually had a higher perceived security, perhaps reflecting travel choices that fulfilled these security predilections; the strength of this relationship is even stronger among women.

Finally, examining the Mexipuerto CETRAM-associated RFID- equipped vehicles and whether knowledge of this ICT-enabled monitoring and organisation approach had any association with colectivo passengers' perceived security, the evidence suggests that 'ignorance is bliss', as unawareness of the RFID devices was associated with a higher sense of security, an effect compounded for women. Being aware of the system and feeling modestly positive towards its impact on security are associated with higher levels of on-board security; again, effects strengthened for women.

\section{Limitations and Future Research Possibilities}

The findings and interpretations above regarding the CETRAMs and colectivo users' security perceptions should be viewed as preliminary and indicative, at best. Our fundamental objective was to demonstrate 
the potential value of new ICT technologies for enabling quick, high resolution urban mobility diagnostics. The approach represents an early trial, intended to chart a path for more rigorous applications. The technology proved reasonably reliable, but the findings may be overly error-prone. Survey implementation depended upon young university students with limited training, which may have impacted the sampling procedure in unknown ways. The survey instrument, designed to be quickly and easily deployed on often crowded vehicles, may be unreliable (for example, inclined towards user error) as may be the indicators themselves (for example, varying interviewee interpretations of the term 'security'). The validity of the dependent variable was also untested. Numerous potentially relevant socioeconomic characteristics, most notably, income, were excluded. While facilitating speed of implementation without discouraging respondents from participating, these omissions are likely to influence the results and certainly hamper generalisability. Similarly, we covered only a single week, during the summer break, and limited travel periods: afternoon off-peak and evening peak.

The research design itself could be improved, as we only chose four routes; the 'control' route may not have been a reasonable comparator and the companies operating each may not be more broadly representative of colectivo services in Mexico City. Finally, as surveyed security perceptions apparently varied widely across the extent of the corridors (Figure 5.5), our analysis would be improved with additional details characterising the physical, socioeconomic, demographic and actual security (for example, crime levels) conditions along the extent of the corridors studied.

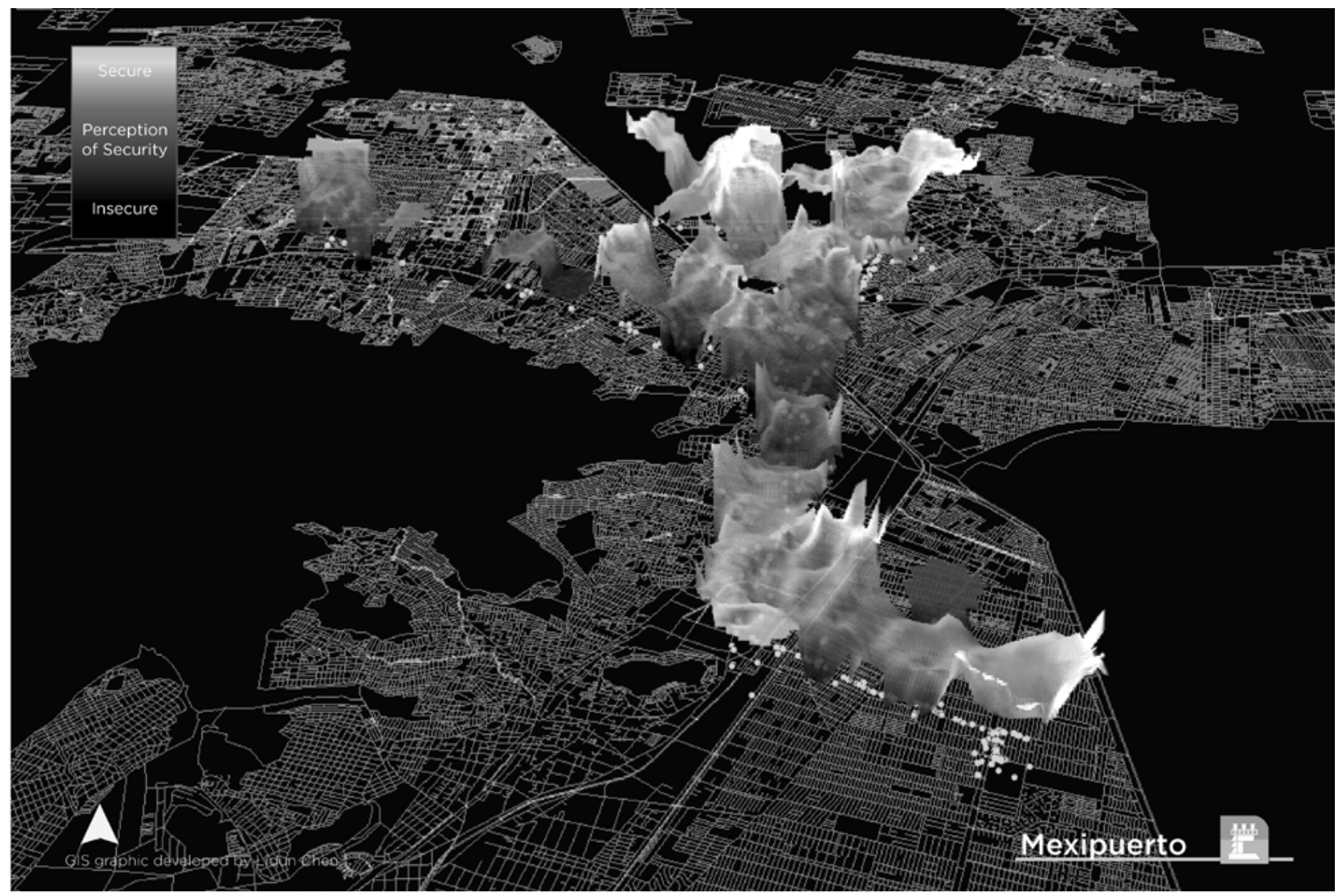

Figure 5.5. Virtual "topography" of user-reported public security perceptions on the routes. 
Although in theory the technology allows precise spatiotemporal matching of survey responses with vehicle conditions (for example, crowding), performance (for example, speeds), and context, our technological trial faced practical challenges regarding these ends. Vehicle crowding may affect security perceptions by increasing user anxiety and stress (House of Commons, 2003), but we did not compile complete crowding metrics in the course of the fieldwork. Technological limitations (that is, geolocating difficulties which 'bounced' some upload points) also prevented us from generating precise speed measures along the full extent of the corridors. These problems related to the still primitive nature of the app we deployed, which could only call one function at a time and thus faced challenges in allocating time to geolocating, carrying out surveys, or uploading data. This stands in contrast to the TransitWand implementation available at the time, which did not have on-board surveying capabilities and required manual data uploads. The manual uploads allows the app to work in areas with weak network service and allows for fewer conflicts with other actions on the device (for example, geolocating, counting), an advantage over the Flocktracker version we used. The downsides to the manual upload approach include the risk of losing data if a phone is damaged or stolen before an upload and the inability to monitor the field data collection remotely in real-time for validation and safety concerns (as in Figure 5.3).

The need for some of these tradeoffs has been reduced with the latest version of Flocktracker, which we piloted in Mexico City in January 2014. Moving beyond the Applnventor 1 built prototype, we developed a natively coded app, with more user-friendly features (including colours better suited to working in glare): an index page that enables full naviga- tion on the app; a counter which does not impede simultaneous surveying; a statistics page to keep track of progress, location, trip attributes and so on; a customisable survey composition feature which allows research projects to easily create their own survey instruments/questions; and the ability to run persistent background processes, which among other benefits allows the Android device to sleep during inactive periods, which is an important battery saver (initial pilots reveal nearly double the battery life over our earlier version). The tool is now ready to develop richer portraits of safety perceptions, consistent with the 'whole journey approach' (Smith, 2008), as well as to aid a broad range of field-based inquiries in transportation or other sectors.

\section{$5 \quad$ CONCLUSIONS}

The smartphone, epitomising the ongoing global ICT transformation, promises to change the way we understand, plan, operate and use urban mobility systems. We examined the smartphone's potential as a mobility diagnostics tool, using it to measure public transport users' personal security perceptions and how they might be related to infrastructure improve- ments, specifically Mexico City's intermodal stations, or CETRAMs. Efforts to improve CETRAMs via real estate-oriented PPPs are consistent with relatively recent moves towards increased 'privatisation' of public safety in the city, including through the use of advanced technology. Deploying a team of volunteers armed with a purpose-built smartphone app, we collected data from over 1000 users of colectivos whose routes passed through or proximate to two revamped CETRAMs in the metropolis' northeast and northwest.

We find little relationship between the CETRAMs and sense of secu- rity among users of colectivos; passengers on vehicles in proximity to CETRAMs report higher personal security levels, but those positive context relationships are similar to those associated with a range of other contexts where the on-board surveys were conducted. We do find a range of contextual settings relate positively to security perceptions, but more research will be required to understand why. Those believing strongly in the 
safety benefits of RFID-equipped vehicles report higher security levels on board (whether the vehicle has RFID or not); this modest ICT technology is associated with even higher levels of security among women, who view it favourably. Younger passengers report higher levels of personal security, while the welleducated do not. Unsurprisingly, gender matters, with female respondents in general reporting lower levels of security, and female-specific effects detected for trip, context and security perception-related variables.

While showing the viability of the smartphone as an urban diagnostic tool, the research faces numerous limitations, which suggests the above results should be viewed as preliminary. The survey was limited in temporal scope, implemented by student volunteers, and collected the bare minimum information from colectivo users. The validity and reliability of measures for the dependent variable can be questioned, and additional contextual information (speeds, physical and social surroundings) should be incorporated into future analyses. The newer version of the app we deployed for this data collection represents a major advancement, which we aim soon to make widely available and envision it ultimately being deployed by anybody with interests in better understanding urban phenomena. In our continuously urbanising world, we hope that increasingly powerful ICT technologies like the smartphone can be used to better diagnose and develop urban mobility systems.

\section{ACKNOWLEDGEMENTS}

This Chapter is based upon research produced through fieldwork supported by a grant from MISTI Mexico and in a partnership with Urban Travel Logistics (UTL). Additional research support came from the Singapore National Research Foundation under the SMART Future Urban Mobility Research Group. We thank Florencia Serrania and Isaac Lozada of UTL for all the support in carrying out the fieldwork. Special thanks also to Gabriel Hernandez of UNAM, Griselda Gomez at MIT-Mexico, MIT graduate students Liqun Chen, M. Bin Jung, and Clara Suh, for their collaboration and contributions and the numerous volunteers who helped carry out the field work.

\section{REFERENCES}

Berg, M., P. Pokharel, A. Sweetland and V. Modi (2013), 'Cellular Citizenship', Harvard International Review, 34 (3), 28-32.

Cottrill, C., F. Pereira, F. Zhao, I. Dias, H.B. Lim, M. Ben-Akiva and C. Zegras (2013), 'Future Mobility Survey: Experience in Developing a Smart-Phone- Based Travel Survey in Singapore', Transportation Research Record, 2354, 59-67.

Davis, D. (2007), 'Urban Violence, Quality of Life, and the Future of Latin American Cities: The Dismal Record So Far and the Search for New Analytical Frameworks to Sustain the Bias Towards Hope', in Garland, A., M. Massoumi and B. Ruble (eds), Global Urban Poverty: Setting the Agenda, Washington, DC: Woodrow Wilson International Center for Scholars, pp. 57-87.

Davis, D. (2013), 'Zero-Tolerance Policing, Stealth Real Estate Development, and the Transformation of Public Space: Evidence from Mexico City', Latin American Perspectives, 20 (2), 53-76.

Eros, E., S. Mehndiratta, C. Zegras, K. Webb and M.C. Ochoa (2014), 'Applying the General Transit Feed Specification (GTFS) in the global south: Experiences in Mexico City and beyond', Transportation Research Record, 2442, 44-52. 
Gobierno del Distrito Federal (GDF) (2011), 'Evaluación del diseño e instrumen- tación de la política de transporte público colectivo de pasajeros en el Distrito Federal', accessed 18 January 2014 at: http://www.evalua.df.gob.mx/files/reco mendaciones/evaluaciones_finales/ev_transp.pdf.

González, M., C. Hidalgo and A-L. Barabási (2008), 'Understanding Individual Human Mobility Patterns', Nature, 453, 779-82.

House of Commons (2003), Overcrowding on Public Transport. Seventh Report of Session 2002-03. Volume I, 17 September, London: The Stationery Office.

Hsu, H-P. (2011), 'How Does Fear of Sexual Harassment on Transit Affect Women's Use of Transit?' Women's Issues in Transportation: Transportation Research Board Conference Proceedings, 46 (2), 8594.

INEGI (2000), Distrito Federal, XII Censo General de Población y Vivienda 2000, TabuladosBásicos, Mexico City: National Statistics Institute.

INEGI (2010), Censo de Población y Vivienda 2010, Mexico City: National Statistics Institute.

Jariyasunant, J., M. Abou-Zeid, A. Carrel, V. Ekambaram, D. Gaker, R. Sengupta and J. Walker (2014), 'Quantified Traveler: Travel Feedback Meets the Cloud to Change Behavior', Journal of Intelligent Transportation Systems (forthcoming).

Lynch, G. and S. Atkins (1988), 'The Influence of Personal Security Fears onWomen's Travel Patterns', Transportation, 15, 257-77.

Newton, A. (2004), 'Crime on Public Transport: "Static" and "Non-Static" (Moving) Crime Events', Western Criminology Review, 5 (3), 25-42.

SETRAVI (2010), Programa Integral de Transporte y Vialidad 2007-2012, Mexico City: La Secretaría de Transportes y Vialidad del Gobierno del Distrito Federal. Smith, M. (2008), 'Addressing the Security Needs of Women Passengers on Public Transport', Security Journal, 21, 117-33.

Sutton, R. and S. Farrall (2005), 'Gender, Socially Desirable Responding and the Fear of Crime: Are Women really more Anxious about Crime?’, British Journal of Criminology, 45 (2), 212-24.

Yavuz, N. and E. Welch (2010), 'Addressing Fear of Crime in Public Space: Gender Differences in Reaction to Safety Measures in Train Transit', Urban Studies, 47 (12), 2491-515.

Zegras, P.C., E. Eros, K. Butts, E. Resor, S. Kennedy, A. Ching and M. Mamun (2015), 'Tracing a Path to Knowledge? Indicative User Impacts of Introducing a Public Transport Map in Dhaka, Bangladesh', Cambridge Journal of Regions, Economy and Society, 8 (1), 113-129. 


\begin{tabular}{|c|c|c|c|c|}
\hline Variable & Description & All & Female & Male \\
\hline Combi & Trip made on combi (van) & 0.68 & 0.73 & 0.64 \\
\hline Pesero & Trip made on pesero (minibus) & 0.32 & 0.27 & 0.36 \\
\hline Mexipuerto & Trip in Mexipuerto study area & 0.47 & 0.49 & 0.45 \\
\hline El Rosario & Trip in El Rosario Study Area & 0.53 & 0.51 & 0.55 \\
\hline CETRAM Route & Route passes through CETRAM & 0.45 & 0.47 & 0.42 \\
\hline Mex_Route & Route through CETRAM Mexipuerto & 0.23 & 0.25 & 0.21 \\
\hline ER_Route & Route through CETRAM El Rosario & 0.22 & 0.22 & 0.21 \\
\hline $\begin{array}{l}\text { CETRAM } \\
\text { Distance }\end{array}$ & $\begin{array}{l}\text { Distance from CETRAM (Euclidean } \mathrm{km} \text { ) at } \\
\text { time of interview }\end{array}$ & $\begin{array}{r}5.21 \\
(5.2 ; 0.04 ; 28)\end{array}$ & $\begin{array}{r}5.16 \\
(5.1 ; 0.04 ; 28)\end{array}$ & $\begin{array}{r}5.27 \\
(5.36 ; 0.06 ; 28)\end{array}$ \\
\hline Mex_Dist & $\begin{array}{l}\text { Distance from Mexipuerto (Euclidean } \mathrm{km} \text { ) } \\
\text { at time of interview }\end{array}$ & $\begin{array}{r}3.47 \\
(5.66 ; 0 ; 28)\end{array}$ & $\begin{array}{r}3.46 \\
(5.52 ; 0 ; 28)\end{array}$ & $\begin{array}{r}3.47 \\
(5.82 ; 0 ; 28)\end{array}$ \\
\hline ER_Distance & $\begin{array}{l}\text { Distance from El Rosario (Euclidiean } \mathrm{km} \text { ) at } \\
\text { time of interview }\end{array}$ & $\begin{array}{r}1.75 \\
(2.7 ; 0 ; 18.5)\end{array}$ & $\begin{array}{r}1.70 \\
(2.8 ; 0 ; 18.5)\end{array}$ & $\begin{array}{r}1.80 \\
(2.72 ; 0 ; 9.39)\end{array}$ \\
\hline Mex_Route_Dist & $\begin{array}{l}\text { Distance from Mexipuerto (Euclidean km), } \\
\text { route through CETRAM }\end{array}$ & $\begin{array}{r}1.57 \\
(4.1 ; 0 ; 28)\end{array}$ & $\begin{array}{r}1.78 \\
(4.4 ; 0 ; 28)\end{array}$ & $\begin{array}{r}1.35 \\
(3.8 ; 0 ; 28)\end{array}$ \\
\hline ER_Route_Dist & $\begin{array}{l}\text { Distance from El Rosario (Euclidean km), } \\
\text { route through CETRAM }\end{array}$ & $\begin{array}{r}0.76 \\
(2.16 ; 0 ; 18.5)\end{array}$ & $\begin{array}{r}0.77 \\
(2.22 ; 0 ; 18.5)\end{array}$ & $\begin{array}{r}0.75 \\
(2.1 ; 0 ; 9)\end{array}$ \\
\hline peak & Trip during Peak & 0.5 & 0.51 & 0.49 \\
\hline age_0_17 & Subject is $0-17$ years old & 0.08 & 0.08 & 0.08 \\
\hline age_18_24 & Subject is $18-24$ years old & 0.25 & 0.22 & 0.29 \\
\hline age_2544 & Subject is $25-44$ years old & 0.40 & 0.39 & 0.41 \\
\hline age_45_64 & Subject is $45-64$ years old & 0.19 & 0.20 & 0.18 \\
\hline age_65 & Subject over 65 & 0.04 & 0.04 & 0.03 \\
\hline companions0 & Subject traveling alone & 0.61 & 0.53 & 0.70 \\
\hline companions1-2 & Subject traveling with 1-2 companions & 0.27 & 0.31 & 0.24 \\
\hline companions3-4 & Subject traveling with 3-4 companions & $0 / 06$ & 0.09 & 0.03 \\
\hline companions5+ & Subject traveling with $5+$ companions & 0.01 & 0.02 & 0.00 \\
\hline Ed_Primary & Subject has primary school education & 0.07 & 0.09 & 0.05 \\
\hline Ed_Secondary & Subject has secondary school education & 0.22 & 0.23 & 0.21 \\
\hline Ed_HighSchool & Subject has high school education & 0.41 & 0.35 & 0.47 \\
\hline Ed_Univ & Subject has university degree & 0.23 & 0.25 & 0.22 \\
\hline Ed_Grad & Subject has post-graduate degree & 0.01 & 0.01 & 0.01 \\
\hline Recreation & Subject on recreation trip & 0.15 & 0.17 & 0.14 \\
\hline Shopping & Subject on shopping trip & 0.12 & 0.14 & 0.09 \\
\hline School & Subject on school trip & 0.07 & 0.08 & 0.07 \\
\hline Work & Subject on work trip & 0.41 & 0.33 & 0.50 \\
\hline Other & Subject on other trip & 0.20 & 0.22 & 0.17 \\
\hline Mode Security 1 & Perception of security on mode (low) & 0.23 & 0.27 & 0.18 \\
\hline Mode Security 2 & Perception of security on mode & 0.11 & 0.11 & 0.11 \\
\hline Mode Security 3 & Perception of security on mode & 0.36 & 0.33 & 0.39 \\
\hline Mode Security 4 & Perception of security on mode & 0.19 & 0.18 & 0.21 \\
\hline Mode Security 5 & Perception of security on mode (high) & 0.08 & 0.07 & 0.09 \\
\hline
\end{tabular}




\begin{tabular}{|c|c|c|c|c|}
\hline Variable & Description & All & Female & Male \\
\hline Point Security 1 & Perception of security at current loc. (low) & 0.22 & 0.24 & 0.21 \\
\hline Point Security 2 & Perception of security at current location & 0.12 & 0.13 & 0.11 \\
\hline Point Security 3 & Perception of security at current location & 0.30 & 0.29 & 0.32 \\
\hline Point Security 4 & Perception of security at current location & 0.21 & 0.20 & 0.23 \\
\hline Point Security 5 & Perception of security, current loc. (high) & 0.11 & 0.10 & 0.11 \\
\hline Security Impt 1 & Importance, security in mode ch. (low) & 0.01 & 0.01 & 0.02 \\
\hline Security Impt 2 & Importance of security in mode choice & 0.01 & 0.00 & 0.02 \\
\hline Security Impt 3 & Importance of security in mode choice & 0.05 & 0.03 & 0.06 \\
\hline Security Impt 4 & Importance of security in mode choice & 0.08 & 0.06 & 0.10 \\
\hline Security Impt 5 & Importance, security in mode ch. (high) & 0.82 & 0.85 & 0.78 \\
\hline PeseroSafest & Subject ranks Pesero as safest mode & 0.06 & 0.06 & 0.05 \\
\hline TaxiSafest & Subject ranks Taxi as safest mode & 0.17 & 0.17 & 0.16 \\
\hline LRTSafest & Subject ranks LRT as safest mode & 0.06 & 0.04 & 0.07 \\
\hline BRTSafest & Subject ranks BRT as safest mode & 0.17 & 0.17 & 0.18 \\
\hline MetroSafest & Subject ranks Metro as safest mode & 0.49 & 0.48 & 0.50 \\
\hline PeserosLeastSafe & Subject ranks Peseros as least safe mode & 0.67 & 0.63 & 0.71 \\
\hline TaxiLeastSafe & Subject ranks Taxi as least safe mode & 0.15 & 0.16 & 0.14 \\
\hline LRTLeastSafe & Subject ranks LRT as least safe mode & 0.03 & 0.03 & 0.03 \\
\hline BRTLeastSafe & Subject ranks BRT as least safe mode & 0.04 & 0.03 & 0.04 \\
\hline MetroLeastSafe & Subject ranks Metro as least safe mode & 0.06 & 0.08 & 0.04 \\
\hline RFID_No & Unaware of RFID-devices on vehicles & 0.65 & 0.66 & 0.65 \\
\hline RFID 1 & RFID has positive security impact (low) & 0.03 & 0.02 & 0.04 \\
\hline RFID 2 & RFID has positive security impact & 0.01 & 0.01 & 0.01 \\
\hline RFID 3 & RFID has positive security impact & 0.15 & 0.13 & 0.16 \\
\hline RFID 4 & RFID has positive security impact & 0.06 & 0.07 & 0.05 \\
\hline RFID 5 & RFID has positive security impact (high) & 0.06 & 0.07 & 0.05 \\
\hline CETRAM & Immediate CETRAM surroundings & 0.11 & 0.12 & 0.10 \\
\hline Res_Streets & Residential streets & 0.30 & 0.32 & 0.27 \\
\hline Suburb_Comm & Large format suburban commercial & 0.30 & 0.02 & 0.04 \\
\hline Ped_Ave & Pedestrian-friendly avenue & 0.02 & 0.02 & 0.02 \\
\hline Auto_Ave & Auto-oriented avenue & 0.15 & 0.13 & 0.16 \\
\hline Express & Expressway & 0.22 & 0.21 & 0.24 \\
\hline Industry & Industrial zone & 0.03 & 0.03 & 0.02 \\
\hline Ped_Street & Pedestrian-friendly secondary streets & 0.08 & 0.09 & 0.07 \\
\hline
\end{tabular}

Appendix: Variables and Descriptive Statistics (percentage respondents or means). $n=1,018$ (526 females, 492 males). For continuous variables values in parentheses, respectively: (standard deviation, minimum, maximum). 